International Journal of Linguistics, Literature and Translation

ISSN: 2617-0299 (Online); ISSN: 2708-0099 (Print)

DOI: 10.32996/ijltt

Journal Homepage: www.al-kindipublisher.com/index.php/ijltt

\title{
Lexical Variation in the Cairene Slum Vernacular and Its Impact on the Prestigious Variety
}

\author{
Dr. Adel Refaat Mahfouz 8 (D) \\ Lecturer in English linguistics, Faculty of Al-Alsun (languages), Minia University, Egypt
}

Corresponding Author: Dr. Adel Refaat Mahfouz, E-mail: adelrefaat56@mu.edu.eg

\section{ARTICLE INFORMATION \\ Received: March 01, 2021 \\ Accepted: April 10, 2021 \\ Volume: 4 \\ Issue: 4 \\ DOI: $10.32996 /$ ijllt.2021.4.4.2}

\section{KEYWORDS}

Cairene slum vernacular, lexical variation, diglossia, variation, and change in Egyptian Arabic

\section{ABSTRACT}

This variationist study attempts to provide an insightful profile of the slum vernacular of the Cairene dialect via formal and social analyses of some vocabulary, phrases, and expressions. It investigates how language varies among the slum speakers in Cairo and what are the social and linguistic roles that this variation plays. The corpus of this study has been attained through close observations, repertoire, and immediate communication with the slum speakers in Cairo. The formal analysis of this study concluded that this variation is often based on the linguistic deviation that poets, dramatists, and novelists use to be creative, inventive, or different. The correlation between the variation and the socioeconomic status of the slum speakers in Cairo is intriguing and suggests that the social setting plays a crucial role in shaping the speech in a given community. The study has revealed that variation in the Cairene dialect functions as an index of the social factors such as socioeconomic status and the area of residence that are distinctive to the Cairene slum communities and helps establish rapport among the slum speakers in Cairo. Moreover, many words and expressions of the Cairene slum vernacular in Cairo have diffused in the prestigious variety for social and linguistic reasons. The study has pointed out that the impact of the Cairene slum vernacular on the youth of the prestigious variety is patent. The two varieties are separably used in their talk and this gives the Cairene dialect a diglossic nature as they confine each variety for some specific uses.

\section{Introduction}

Linguistic variation is a continuous process that affects all languages over time for different reasons. It could be geographical or social. For instance, Geographical dialects and accents are a consequence of the regional variation. Social dialects, register, and style occur as a result of social variation. All aspects of language are prone to variation; it could be lexical, semantic, or phonetic. Lexical variation simply means that the same meaning in dialect $A$ is represented by a different word or expression in dialect $B$ for some geographical or social reasons. Socially speaking, lexical variation, as Stamp et al. (2014) state, "maybe systematically used by speakers to index their affiliation with particular social groups" (p.1). Moreover, variation may happen for communicative purposes as speakers recognize that the new words and expressions may be simpler and more expressive in describing their feelings, their daily routine, or when naming objects around them, or it just occurs, as Ibrahim (2011) claims, as a result of "lexical preferences and diglossia" (p. 13).

This study, however, concerns itself with the lexical variation in the Cairene slum vernacular and its implication on the speakers of the prestigious variety. This variation, however, is neither aimless nor haphazard. Rather, it is dynamic, systematic, and functional; the slum speakers in Cairo think that they can express their unique experiences, needs, and daily situations, which the ordinary communicative devices of the prestigious variety cannot effectively express through such variation. Through lexical variation, the slum speakers in Cairo transcend the normal limits of the lexical rules and functions of the prestigious variety to satisfy their social and linguistic needs. As for the phonetic and phonological variation in the Cairene slums, it has been tackled by the researcher in a separate study.

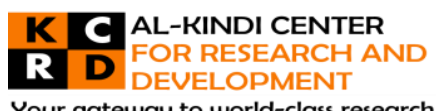

Your gateway to world-class research

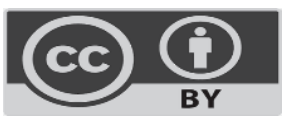

Published by Al-Kindi Center for Research and Development, United Kingdom. Copyright (c) the author(s). This open access article is distributed under a Creative Commons Attribution (CC-BY) 4.0 license 
These linguistic features socially divide the Cairene dialect into two varieties; a prestigious one spoken by people who belong to the high and middle classes and a low one spoken by those who are at the bottom tier of the social hierarchy. This rigid dichotomy between the Cairene slum vernacular and the prestigious variety, one claims, renders the Cairene dialect diglossic. According to Ferguson (1959), diglossia is a situation in which two different language varieties are used by the speakers of a single speech community. Each of the two varieties has a specific domain of social activities confined to it. The one that is used for written and formal spoken purposes is called the high variety or $\mathrm{H}$ and the other one, called the low variety or $\mathrm{L}$, is used in the actual language activities. However, some sociolinguists considered Ferguson's (1959) definition of diglossia narrow and broadened it to include dialects and different languages. Fishman (1967), for instance, extended Ferguson's definition of diglossia to include more than two language varieties, related or unrelated, so long as they do different functions in a speech community. Wardhaugh and fuller (2006) redefined diglossia to "describe a situation in which there are two distinct codes with clear functional separation; that is, one code is employed in one set of circumstances and the other in an entirely different" (p.91).

Holmes (2013) expanded the term to include any two different varieties. She defined diglossia as "a characteristic of speech communities rather than individuals [...] where two varieties are required to cover all the community's domains" (p.30).

Nonetheless, one might argue that neither the classical definition nor the widened ones could apply accurately to the Cairene dialect because the $\mathrm{H}$ and $\mathrm{L}$ varieties are functionally and socially parallel and diglossia is triggered when the varieties are used by the same group in different situations and for different purposes. Nonetheless, the jargon of youth rendered it diglossic; because of the parental and official rejection of the Cairene slum vernacular, the young men and women who belong to the prestigious variety do not use it at home, in serious situations or when they talk to older people. Rather, they use it with friends, on the street, and in casual conversations. This is because, as Nordquist (2020) claims, "using the wrong variety in the wrong situation would be socially inappropriate." Adopting Badawi's (1972) categorization of Egyptian Arabic, one might claim that the diglossic feature in the Cairene dialect is represented in ça:mrjat al-mutanawwrii:n the colloquial of the educated and ca:mijat alummiji:n the colloquial of the illiterate. This categorization, one might claim, supports the hypothesis that the Cairene dialect is diglossic, whereas the jargon of youth triggers it.

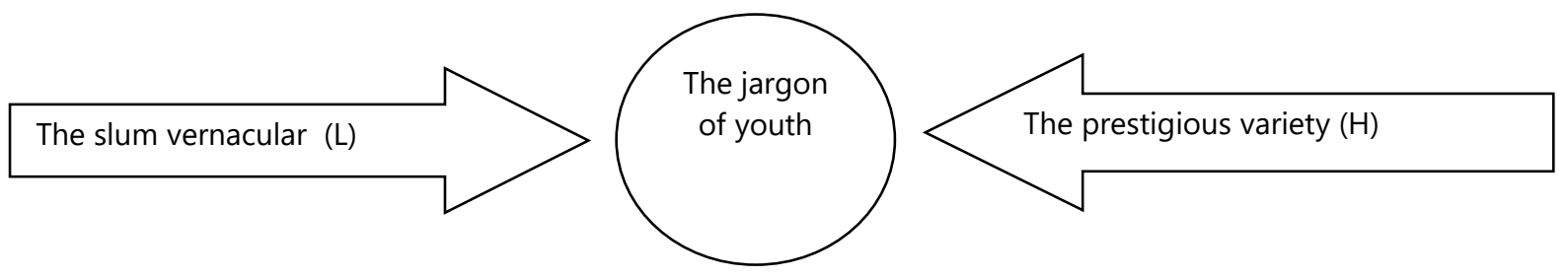

Figure 1: how diglossia is triggered in the Cairene dialect

\section{Review of the literature}

Abdel-Jawad (1981) tackled the lexical and phonological variation in Amman. The aim of the study, according to him, was to provide an objective description of the linguistic status in an Arab speech community. It focused on the relationship between the high and the low varieties via an empirical variationist model. The study revealed that variability in spoken Arabic is fully extralinguistically conditioned and gender plays a significant role in that variation. It also pointed out that the linguistic situation in the Arab world can be described through variation models. Ibrahim (2009) conducted a study on the lexical variation in Egyptian, Lebanese and Moroccan Arabic via newspapers' headlines to show to what extent this variation impedes understanding. Her study was established upon analyzing some morphological and semantic categories such as the use of plural forms of gerund, coining lexical items, the influence of dialect and translation, differences in usage of verb preposition, and choosing different meanings of the same word. The study revealed that Egyptians found it difficult to understand the Lebanese and Moroccan headlines, while the Lebanese participants fully understood the Egyptian headlines. Saleh (2017) retackled Ibrahim's (2009) study, i.e., the study of lexical variation in Egypt, Lebanon and Morocco to investigate the extent of this variation and measure the degree of misunderstanding after the satellite chandelles and social media had spread across the Arab world. The conclusion that Saleh (2017) reached is that "the challenge in understanding the lexical variation among different communities is minimal. It is just the simple natural phenomenon of the language change over time through its users." (p.81).

\section{Methodology and data analysis}

This study is based on data collected by the researcher through observations and direct contact with some of the slum speakers in Cairo. To give an integrated sociolinguistic view, the lexical variation has been subjected to descriptive analysis and social treatment; the different word-formation techniques that the slum speakers in Cairo employ to coin words and expressions, deviation, and vernacularization have been described and their various social functions have been treated. 


\section{Research questions}

Throughout this study, the researcher attempts to address the following questions.

1. Is the Cairene dialect diglossic?

2. Does the socioeconomic status of the slum speakers in Cairo affect their language?

3. How do the members of the other social strata see the lexical variation in the Cairene slum vernacular?

4. Does the Cairene slum vernacular have an impact on the speakers of the prestigious variety?

\section{Formal treatment of data}

To enrich the lexicon of their vernacular and make it more expressive and fulfill their linguistic and social needs, the slum speakers in Cairo employ some lexical and grammatical deviation techniques: unusual collocations, vernacularization, recontextualization, creating new combinations, coining new words, re-forming long-established word forms, clipping, and backformation.

According to Ibrahim (2011), lexical variation is "an area of sociolinguistics which studies differences in certain lexical items used by various speech communities. This phenomenon can be attributed to many variables, such as the nature of the language itself, geography, social status, individual preferences, topic, hierarchy, language academies, media, etc." (p.13). More precisely, Geeraerts, Grondelaers \& Bakema, (1994) define lexical variation as a "contextualized, pragmatic conception of onomasiology, which focuses on the actual choices made for a particular name as a designation of a particular referent" (p.14). In this section, the different techniques that represent the lexical variation in the Cairene slum vernacular are tackled and analyzed.

\subsection{Unusual collocations}

Due to the unconventional combination of lexemes, the semantic relations of words in a phrase or an utterance are odd and logically inconsistent and cannot be accounted for through the dictionary meaning of words. The speakers of the other dialects might find it difficult because they have to look for the new meaning because, as Yule (2003) states, "one way we seem to organize our knowledge of words is simply on the basis of collocation, or frequently occurring together" (p.118). This technique, as Leech (1969) states, is used by poets, novelists, and playwrights to express their feelings, ideas, and views as they strike the minds of their readers with unpredictable combinations. The slum speakers in Cairo, one may claim, adopt this technique to make their speech expressive and attractive. For instance, the following face-value bizarre phrases are widespread in the Cairene slums.

/ ji naunau fi di ma:ghi / lit. to meow in my brain, is used when someone is hunted by some idea or interest.

/ma ja: 'kulf maça:ja/ lit. it doesn't eat with me, is used when something is not acceptable.

/juhrof ?il 'le:la/ lit. to itch the night, is used when someone uncovers a plot or a trick.

/kabbar 'mu**ak/ lit. enlarge your brain, is used when you advise someone to ignore unpleasant situations.

/ji wirr fI 'wida:n/ lit. to urinate in one's ears, means to put up to.

/ja:kul di ma:gh/ lit. to eat someone's brain, means to nag.

/jiffrJ/ lit. to seize, which is originally used with machines with moving parts, is reused by the slum speakers in Cairo to mean be upset or angry.

/jtt' Ja?lib/ lit. to flip is usually used in the imperative mood by superiors meaning to look for someone, something, or a solution for an issue. i.e., to leave no stone unturned.

/ji kammar/ lit. to braise is now used as to conceal or save.

The slum speakers in Cairo arbitrarily widen the semantic domain of some verbs by adding abstract meanings to their concrete ones and using them in different areas of discourse. For instance, the concrete meaning of the verb /jiçal-IIm/ lit. to mark with a scar is used figuratively to mean refute or win a debate. The verb /ju hokk/ lit. to rub or scratch is used to mean to woo. The verb /ji bi:d/ lit. to lay an egg is employed to mean talk rubbish. The verb /ji du:s/ lit. to step on was broadened to mean to indulge. The third-person feminine singular simple past/Ritçaf-frt/ lit. she ate her dinner is used to mean It's been accomplished satisfactorily.

Moreover, the Cairene slum speakers rename some objects by borrowing the names of other substances that have a common appearance, color or shape. One might claim that the renaming is done for euphemistic purposes, namely, they may camouflage the prohibited substances with names of non-prohibited ones to hide debauchery and save face. For example, they use /'budra/ lit. powder for heroin, /' maija/ lit. water for wine, /*a'bu:r/ lit. wedge for joint and /fa ravla/ lit. strawberry for Tramadol pills. That is to say, they employ the socially acceptable words to mitigate the bad connotations of the intended meanings.

In addition to the deviation of words of food used for flirting and sexual harassment, the slum speakers in Cairo recontextualize some other food words. For instance, /Przza tu:na/ lit. the olive means the bottom line, /*am 'i:ra/ lit. yeast means savings, /'balah// 
lit. dates means nonsense, /'Iu?ma ța'rijja/ lit. a tender bite means easy, quick and profitable deal and /'Iu?mit çe:J/ lit. a bite of bread means work.

\subsection{Vernacularization}

One notices that the slum speakers in Cairo vernacularize some formal verbs. That is to say, their functions, according to Holmes (2013), "were extended from exclusively H functions to include L functions" (p.77). Although the verb /jata ' ca:mal/ lit. deal with or face is formal, the slum dwellers in Cairo have vernacularized it to mean get by. Furthermore, vernacularizing and repurposing the verbs with religious connotations in expressing temporal issues are usually spread via movies. Although the verb adore in the French expression je t'adore means to love, Egyptian actors and actresses who starred in the romantic films in the 1940s and 1950s used the other meaning of the verb, i.e., to worship and calqued the expression as /baç budik/ lit. I adore you. In the same vein, the religious verb /'jaștafi/ / lit. to elect messengers was secularized in Al- Raiys Omar Harb lit. Boss Omar Harb movie to mean to select someone for a mission. This time the dwellers of the Cairene slums took the initiative and detached the verb /'jaxjac/ lit. to submit or grovel to Allah from its religious universe. It has been reused by business owners, thugs, and parents when commanding disobedient employees, resisting victims, and naughty children respectively to submit to their authority. The formal verb /jI' havwir/, pronounced by the Cairene slum speakers as /jI' havwar/ lit. to modify some points in a topic, has been vernacularized to mean to beat around the bush, /jI' gauwid/ lit. to improve is used as to brownnose. The formal verb /ji'knif/ lit. to take care of is vernacularized and deviated to mean to harbor a criminal. These highly codified verbs are now used by the Cairene slum speakers in their daily communications.

\subsection{Banter}

The Cairene slum speakers superficially flout the politeness norms when they describe a friend as /7Ibn ha'ra:m/ lit. illegitimate son, /'fa:gir/ lit. licentious, /'ka:frr/ lit. disbeliever, /'mugrım/ lit. criminal, /'ga:hıd/ lit. ungrateful or /'sa:jic/ lit. lowlife. On a deeper level, however, they fully uphold the politeness principle as they mean that this friend is brave, preeminent, competent, and adroit. According to Leech (1983), the goal of using this technique, is to further solidarity and friendliness. Leech (1983, p. 144)) adopts it to form a principle in his Interpersonal Rhetoric Model. He postulated the Banter Principle as follows:

In order to show solidarity with hearer (h), say something which is (i) obviously untrue, and (ii) obvi-ously impolite to h ... What speaker (s) says is impolite to $h$ and it is clearly untrue. Therefore what $s$ really means is polite to $h$ and true.

Amazingly, these words, which are first used by the slum speakers in Cairo to banter with, have acquired long-established positive meanings when used in praising others, regardless of being friends or not.

\subsection{Synonyms}

Synonymy, as defined by Hurford, Heasley, and Smith (2007) "is the relationship between two predicates that have the same sense" (p.106). However, it is difficult to find two predicates that have identical meaning. They may differ in style, formality or the social meaning that marks a speech community. For instance, in the Cairene slums, /cin' na:b/ is used instead of /karka' de:h/

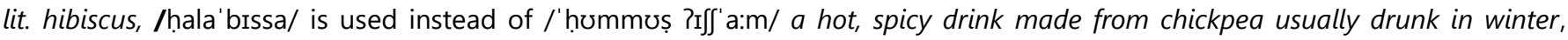
/bonn/ lit. raw coffee replaces /'?ahwa/, lit. coffee /'?u:ța/ substitutes /ta'ma:tım/ lit. tomatoes and /sı'mi:t/ lit. baguette is employed instead of /'fi:nv/.

\subsection{Plural forms}

It is remarkable that creating new plural forms is less obtrusive than the other variation features. Most of the plural words that the researcher could collect are subjected to the plural patterns /fu'çla/ and /fa'wa:çl/. For example, /tu'kusa/ lit. taxis is used

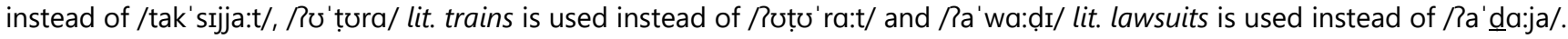

\subsection{Use of objective pronouns with new verbs}

It has been noticed that the slums speakers in Cairo use the objective pronouns with new verbs like /jifta'ghil/ lit. to work and new forms of some other verbs like /jighaf'fil/ lit. to fool. jIfta'ghalna/ and /jighaf'filna/ lit. to fool us. The first-person singular objective pronoun $m e$ is also used instead of the reflexive pronoun myself in /'hamawtni/ lit. I'll kill me and /'hadbahni/ lit. I'll slaughter me.

\subsection{Use of informal diminutive patterns}

According to Naaser (2020), "a diminutive noun is a denominal noun used mainly for expressing the small size of the object denoted" (p.19). Although the informal diminutive pattern /fıc'la:ja/ is applied to some specific nouns by the speakers across Egypt for a specific purpose, i.e., endearment, the slum speakers in Cairo apply the same pattern to some other nouns. For example, forms such as /nașa'barja/ lit. fraud, /nuș'șaija/ lit. half, /*am'sa:ja/ lit. five, /naḩ'ta:ja/ lit. small business or deal, and /dok'ka:na/ lit. small shop are frequently used in the Cairene slums. 


\subsection{Affixation}

It has been noticed that the slum speakers in Cairo add the request morpheme /jist/ at the beginning of some specific verbs, e.g., /jista manna/ lit. to hope, /jista ' cazz/ lit. to cherish, /jis'ta?ḍa/ lit. to get, /jis' țaçța/ lit. to addict are the variants of /jit' manna/, /jIs'tazz/, /'ji?ḍ̂/, /jtt'ca:ta/ respectively. However, this derivational morpheme is deleted in some verbs as in /jis'taghfil/ to be pronounced as /ji'ghaffil/. Although the addition and deletion of this prefix change the form of these verbs, their category is the same. One might think that the goal beyond this deviation is to be expressive and different.

\subsection{Backformation}

The slum speakers in Cairo use this word-formation process to create some new verbs from nouns by subjecting them to /jI' façal/, /jI' faç̧al/, /jI' façıl/ or /jI' faç̧ıl/ patterns. One might claim that these new verbs are coined to bridge a lexical gap; they unconsciously recognize the economy principle as they want to convey more information and save time and effort at the same time. The verbs below do the same function of their verb-object collocations.

/ji'barfat /, lit. to drop in or gatecrash, is backformed from the loanword parachute.

/jI' barfIm/, lit. to swallow pills, is backformed from /bir'ja:m/ lit. pills.

/ji șaddagh/, lit. to smack across the face, is backformed from /șidgh/ lit. temple.

/ji' xazwa?/, lit. to drive a wedge, is back-formed from /xa zu:?/ lit. wedge.

/jI' waggib /, lit. to do someone a favor, is backformed from / wa:gib/ lit. favor.

/jI' mașlah/, lit. to get benefit from a situation in an improper way, is backformed from /maș' laḥa/ lit. business.

/ji' saijjat /, lit. to make famous, is backformed from și:t/, lit. fame.

/jI' nafsin/, lit. to hold a grudge, is backformed from /nafs/ lit. psych.

/jI' fa**ad lit. to live a sedentary lifestyle, is backformed from /fa*d/ lit. thigh.

/jI'ssajjan/ lit. to maintain a vehicle, device, building or machine is backformed from /ssi'ja:na/ lit. maintenance.

\subsection{Clipping}

According to Marchand (1969) clipping is "the reduction of a word to one of its parts" (p.441). The slum speakers in Cairo arbitrarily cut some parts from some words and phrases. For instance, the word /fI' 'i:?/ lit. brother is reduced to /Ja?/, the last part of the proper noun /ma'hammad and the first part of the proper noun /itbra' hi:m/are dropped, and /ma hamma/ and /hi:ma/ are used instead. The morning greeting /șa'ba:h 7.l xe:r/ is shortened to /șa ba:ḥo/. These clipped forms, one may claim, are not used to save time and effort during speaking, but, as Marchand (1969) claims, people use them in their social milieux as a sign of intimacy and solidarity.

\subsection{Neologisms}

According to Leech (1969), "neologism, or the invention of new words [...] is not the prerogative solely of the poet [...]. Even ordinary citizens in ordinary conversations quite often stumbled into neologism as the readiest way to express their feelings or opinions" (p.42).

Conversational neologism is often innovated by a single speaker to fulfill a single need on a single occasion. Moreover, the slum speakers in Cairo may resort to coinage when they feel that the equivalent in the prestigious variety is not expressive enough. It has been observed that the new words are meaningless and sound odd, yet they acquired meaning through the situation they are first used in and familiarity from frequent use. /misti'kanjas/ lit. nonchalant, /'sarsagi/ lit. lowlife, /si:ka/ lit. little bit/, /mi'?affar lit. broke, /jrf'trkis/ lit. innovate, /jI'?abig/ lit.to pay and /jI'Jahjas/ lit. to pamper are some examples of the new adjectives, nouns and verbs created by the slum speakers in Cairo. Although these innovations have diffused in the different dialects across Egypt, their status is still uncertain. In other words, one cannot predict whether they will be nonce or longestablished entries in the Egyptian colloquial diction.

\subsection{Functional shift}

Although they are morphologically and syntactically different, the slum speakers in Cairo use some nouns in the slot of other nouns and adjectives, particularly in the vocative case. For example, they say ta'ça:la ja rı'gu:la/ lit. come on, manhood! instead of /ta'ça:la ja 'ra:gil/ lit. come on, man! In the same vein, /ka'fa:?a/ lit. competence is used instead of /kuf?/ lit. competent, /dak'tara/ lit. doctorship instead of /duk to:r/ lit. doctor, /han' daza/ lit. engineering is used instead of /baJmu'handis/ lit. engineer, /3an'tala/ lit. gentlemanhood is used in the place of /'3intrl/ lit. gentleman, /ri' ja:sa/ lit. presidency substitutes /'raijs/ lit. president, and /hubb lit. love replaces /ha'bi:bi/ lit. my beloved. In other words, they personify abstract ideas, names of careers, and jobs by giving them some human attributes and reuse them as endearment terms. 


\section{Social treatment of data}

\subsection{Variation and behavior}

The illegal and immoral activities of some of the slum speakers in Cairo are clearly reflected in their diction. Since sexual harassment, immoral relationships, and narcotics addiction are rife amongst the slum speakers in Cairo, one claims that the words that represent these activities emerged there as a nonce. the sexually suggestive words that describe women's bodies are loudly said out to young women in public places. such as /'bațal/ lit. hero, /sa ru:*/ lit. rocket, /'muzza, might be derived from /'mazza/ lit. nibbles, /'malban/ lit. Turkish delight, /çasa'Irjja/ lit. candy made from dried molasses, and /'wataka/ lit. curvy are massively used in these slums. One may argue that such deviations are employed to cause a psychological effect on women and girls by striking them with unexpected body descriptions and forcing them to react. Words like /rafa?/lit. mistress, /Ji ma: I/ lit. left, /has' ha:na/ lit. sexually aroused, and the derogatory plural form of women /nis'wa:n/, which allude to sex, are deviated to describe women of ill repute. Many words associated with drugs are frequently heard in the Cairene slums too. For example, /*a'bu:r/ lit. joint, /'maija/ lit. water for wine, /'budra/ lit. powder for heroin, /fa'ravla/ lit. strawberry for cheap pain killer Tramadol, as well as the verbs that collocate with them such as /jIf'Jid/ lit. to toot, /jI'?arbaç/ lit. to booze, /ji'balbac/ lit. to swallow, /ji' drab/ lit. to do drugs constitute a part of their diction. Even the anomalous formation of the word /'mukna/ lit. place and the word /'ghorza/ lit. den give the connotation of committing an illegal or/and immoral action in them.

The dwellers of the Cairene slums picked up on one kinship term and confined its use to express understatement, bullying, mocking, or showing defiance by creating the bizarre formation (ok + uncle + definite article+ adjective or noun). Mazid (2020) states that the unreal use of kinship terms is sometimes meant by Egyptians to express endearment or understatement. Mahmoud (2016) argues that using the variants of some kinship terms by the speakers of the lower class in negative contexts is intended "to humiliate the addressee" (p.9).

This unfriendly manner of expression usually comes as a quick echo answer to someone who pretends the attribute that the adjective names or has some characteristics that the noun identifies. For instance, if someone pretends to be funny, his interlocutor can comment sarcastically using the same adjective, /'ma:JI ja 'çamm ? $\mathrm{Iz}^{\complement} \mathrm{z}^{\complement} \mathrm{a}^{\prime}$ 'ri:f/ lit. ok, uncle funny! An obese person may be bullied by using the word /fi:l/ lit. elephant, as in /'ma:Ji ja 'çamm ?il fi:l/ lit. ok, uncle elephant! The most popular adjectives and nouns that are used in this combination are:

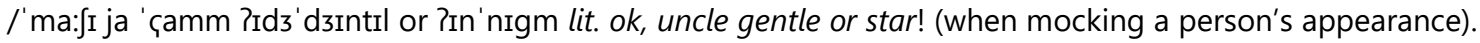

/'ma:JI ja 'çamm ?If'Jabah. lit. ok, uncle ghost! (when mocking a person's agility and strength).

/'ma:Ji ja 'çamm ?llbaț'ri:q/ lit .ok, uncle penguin! (when mocking a person's gait).

/'ma:Ji ja 'çamm ?ırrı'ja:ḍI/ lit ok, uncle athlete! (when mocking a person's sturdy physique).

\subsection{Variation and socioeconomic status}

One could claim that the low economic status of the overwhelming majority of the Cairene slum dwellers influences the coinage and formation of the words they use. The redundant use of the informal quantifier word /JI'warja/ lit. some that precedes some kinds of food and drinks as well as the diminutive forms of some words evidently reflects the relationship between the economic status as a social factor and language use. When the slum speakers in Cairo place an order in a coffee shop or a restaurant, they insert the quantifier / $\mathrm{I}$ 'warja/ lit. some or a small amount of before the words that the other social classes do not use. For

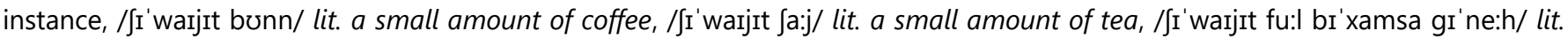
five pounds worth a small amount of beans. One could claim that although cup and five pounds worth of are ample to specify the amount, the quantifier /JI' warjit/ is routinely added before the order as an expression of their poverty, i.e., the quantifier here is socially employed. Similarly, although the non-standard diminutive pattern /fıc'la:na/ is used by other classes, the slum speakers in Cairo use it with some specific words for endearment and showing affection. For example, words like /bumbu'na:ja/ lit. as sweet as bonbon, Rama'ra:ja/ lit. as beautiful as the moon, /çasa' Irjja/ lit. as sweet as honey are heard in the upscale districts and slums alike. The Cairene slum dwellers, however, utilized this pattern with some new words to mirror their hard life and miserable economic conditions. It is common to hear words like /rub' ca:ja/ lit. quarter, /nuș'ṣa:ja/ lit. half, /xam' sa:ja/ lit. five, /ça' ra:ja/ lit. ten and the amazing word /nah'ta:ja/ lit. a hard small piece of rock cut with a chisel to refer to hard small business with little profit. The diminutive form /dv ka:na/ lit. small shop, regardless of its space, is also used for the same reason.

Even the sweet words which they use to flirt with women are conditioned by the economic status of the underdog. They use cheap /'malban/ lit. Turkish delight to refer to women's soft white complexion and /çasa'IIjja/ lit. candy of poor quality made of dried molasses to describe prettiness.

Feeling socially and economically inferior to the speakers of the other variety, the slum speakers in Cairo excessively use words of apology although they do not commit what they should apologize for. Their vulnerable position and lack of confidence oblige them to express apology if they have a different point of view; expressions like /'çadam ?il'lamu '?axza/, /'lamu '?axza fil 'kilma/ and /mat?axiz' ni:J/ lit. excuse my French have been reused to mean sorry for having a different point of view. Moreover, the 
humiliating thank-you words such as /Ra'xu:k ?izu' ghaijar/ lit. your younger brother, /xad' da:m 'naçalak lit. a servant for the sole of your shoes, and /mah'su:bak/ lit. I'm your servant, which are usually said by the slum speakers in Cairo after receiving any due money, spring from and reflect the low socioeconomic status of the Cairene slum dwellers.

Religious words and expressions, as Mazid (2021) states, are used by the different social strata across Egypt for different communicative purposes, irrespective of being religious or not. The slum speakers in Cairo, however, specialize certain expressions and alter their wording and functions when they flaunt their prosperity, abilities, or accomplishments. These expressions are not meant literally, but they are pragmatically utilized; they are used as disarming to save their positive face. That is, in order not to be accused of snobbery or shunned by their interlocutors, they coat their braggadocio with these expressions. Thus, they can show off humbly! The frequent religious expressions such as /br'?tznak ya rabb/ lit. God willing, /'srka fil'la:h/ lit. I trust in Allah, /bi'çu:n ?II' la:h/ lit. I seek assistance in Allah, and /'Zana wa ?' '̧u:zo bil' la:h min '?o:It '?ana/lit. I seek refuge in Allah from having a big ego, therefore, are used for some social and pragmatic purposes.

\subsection{The impact of variation on the speakers of the other classes}

Through close observations, one might claim that the youth of the high class are more tolerant of the Cairene slum vernacular variation than old people. They use some linguistic features of the Cairene slum vernacular to fulfill some social, psychological, and linguistic needs. Many adolescents rebel against the norms of the class to which they belong and have a natural tendency to experience the thuggery life that many of the words and expressions of the Cairene slum vernacular realize. As a result, they adopt some words and expressions of the Cairene slum diction which break the linguistic rules of the prestigious variety that they rebel against. That is to say, the linguistic deviation they adopt is a manifestation of a social deviation. Some others see it as a sign of chivalry and manning up. Another sect of adolescents considers the slum words and expressions more expressive than theirs. Although they subject these words and expressions to the phonological system of the prestigious variety to which they belong, they remain as jargon amongst adolescent speakers. However, the meaning of many obscene words and expressions has been mitigated due to the new usages of the youth's jargon. For instance, /mar' laça/, a sexually suggestive word, is used to mean procrastination and /'muhn/ lit. lust is employed to mean fake and/or over cuteness. The families of the adolescent speakers, on the other hand, have overtly negative attitudes towards the Cairene slum vernacular as they consider it a sign of vulgarity and ill-manners. Sadiq (2016) argues that the Cairene slum vernacular "is generally stigmatized. The stigmatisation is mainly due to lexical variations, voice quality and accompanying linguistic behaviour in these slums" (p. 28).

Sociologically speaking, although this variation reflects the social and economic statuses of the slum speakers in Cairo, it demonstrates how the teenagers of the other social classes stick to the norms of the culture that these words represent.

The linguistic deviation, which is characterized by unexpectedness and breaking the normal linguistic rules, expands the communicative gap between the slum speakers in Cairo and the old speakers of the prestigious variety and may change the vernacular into an argot. The following utterances, for instance, are very difficult for the speakers of the other classes to understand.

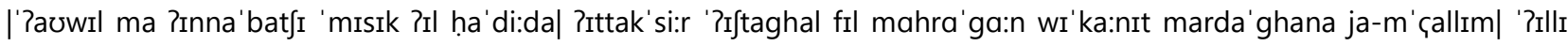

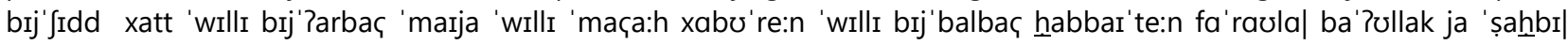
ma'ça:ja hrtta 'habbu mikam' mara ma-'ti:gr ni'davar 'çala 'mokna nIf'rabha 'fi:ha|

They can never think of them as,

No sooner had the wedding Master of Ceremonies held the microphone than breakdancing began. It was a dog's dinner; the guests were tooting, boozing, smoking joints and swallowing some Tramadol pills. Bro! I've a piece of premium hash. What about looking for a den to smoke it in?

Or consider the following exchange,

/ta:xud ma'ca:k ?ad ?e:h/ How long does it take?

/nuș'șa:ja ças' sa*a:n/ In no time! Just half an hour!

/ttt' kallıf ka:m/ How much does it cost?

/xam'si:n 'gundi/ Fifty pounds!

This makes the speakers of the high variety think that the slum dwellers speak an argot, albeit unintentionally. The lexical variation that marks the speech of the slum speakers in Cairo sometimes sends a negative signal to the speakers of the other social classes, particularly old people, and eventually leads to social ostracism. Furthermore, the spread of such lexical innovations among the youth of the high variety and other dialects across Egypt comes at the expense of the diction of the high variety and the other dialects and may spoil the values of the society as most of them are associated with obscenity and offensiveness. 


\section{Conclusion}

The lexical variation, unlike phonetic variation, is dynamic, arbitrary, and unpredictable. So, it could impede understanding and may lead to communication failure in case the other converser is not well-acquainted with the new meanings that words have acquired due to the linguistic deviations.

Sociolinguistically speaking, borrowing is a downward activity; the higher social strata are usually imitated by middle and lower classes. In the case under study, one notices that the speakers of the other social classes are now borrowing some words and phrases from the Cairene slum diction. That is to say, borrowing can be a downward-and-upward process; in a win-win situation, the speakers of the higher social class, particularly youth, equip the Cairene slum vernacular with some of their words and expressions particularly foreign loanwords, whereas the slum speakers in Cairo provide them with some lexical variants and new expressions that satisfy their social and linguistic needs.

Thanks to the social media, the growing exposure to the lexical variants through daily communications with the slum speakers in Cairo, movies, and pop songs mahraganat, the boundaries between the two Cairene varieties are being eroded and the Cairene vernacular has gained new speakers; although one cannot measure the new status it has acquired, it constitutes at this juncture many aspects of the culture and jargon of the present-day youth across Egypt. Despite this de facto status, it is rejected by parents, official media, and highly educated people. Moreover, this variation apparently reflects the values and socioeconomic status of the slum speakers in Cairo; many of the coinages are obscene or coarse; they revolve around narcotics habit, drinking alcohol, and sexual abuse. Besides, the excessive use of apology expressions and thank-you words, when communicating with people from a higher social class, mirrors the social inferiority that the slum speakers in Cairo feel. One might claim that one of the most important findings of this study is refuting the sociolinguistic truism that poverty plays a key role in language death and speakers, as Batibo (2009) claims, "tend to identify themselves with the most socioeconomically prestigious language." The study has revealed that the slum speakers in Cairo use their vernacular in their daily communications and the vivid variation is strong evidence that low socioeconomic status is not always a critical factor in language death. Finally, it is hoped that this study opens the door for more comparative studies on the various types of variation in the different social and regional dialects in Egypt.

\section{References}

[1] Abdel-Jawad, H. R. (1981). Lexical and phonological variation in spoken Arabic in Amman. [Unpublished Ph.D. thesis]. The University of Pennsylvania, Philadelphia.

[2] Badawi, S. M. (1972). Mustawayāt Al-'Arabiyya al-mu'āşsira fĩ Mişr [Levels of contemporary Arabic in Egypt]. Cairo: Dār Al-Ma'ārif Publishing House

[3] Batibo, H. (2009). Poverty as a crucial factor in language maintenance and language death: Case studies from Africa. In W. Harbert, et al (eds.), Language and Poverty (p.23): Multilingual Matters Ltd

[4] Ferguson, C. (1959). Diglossia. Word, 15, 325-40. Geeraerts, D., Grondelaers, S., \& Bakema, P. (1994). The structure of lexical variation: Meaning, naming, and context. Berlin/Boston: De Gruyter Mouton

[5] Fishman, J.A. (1967). Bilingualism With and Without Diglossia; Diglossia With and Without Bilingualism. Journal of social issues, 23(2): 2938, https://doi.org/10.1111/j.1540-4560.1967.tb00573.x

[6] Holmes, J. (2013). An introduction to sociolinguistics. Routledge

[7] Hurford, J.R, Heasley, B., \& Smith, M.B. (2007). Semantics: A coursebook. Cambridge: Cambridge University Press

[8] Ibrahim, Z. (2011). lexical variation: Modern Standard Arabic. Encyclopedia of Arabic language and linguistics. Retrieved 21 ${ }^{\text {st }}$ January 2021, from http://bit.ly/36ovWqS

[9] Ibrahim, Z. (2009). Beyond lexical variation in Modern Standard Arabic: Egypt, Lebanon \& Morocco. Newcastle: Cambridge Scholars Publishing.

[10] Leech, G. (1969). A Linguistic guide to English poetry. London: Routledge

[11] Leech, G. (1983). Principles of pragmatics. New York: Longman

[12] Mahmoud, A. H. R. (2016). Variants of nominal forms of address in Egyptian settings. Proceedings of Linguistic Im/politeness and Rudeness IV. Retrieved $11^{\text {th }}$ February 2021, from https://www.academia.edu/45087442/

[13] Mazid, B. M. (2021, Jan. 14) Shaçab mutadaiyn bitabçuh [Inherently religious people]. Retrieved $21^{\text {st }}$ January 2021, from http://bit.ly/3pAHteg

[14] Mazid, B. M. (2020, December 2) camm ?oul ya rabb [O' uncle! Say O' Lord!]. Retrieved 2 ${ }^{\text {nd }}$ January 2021, from http://bit.ly/3ab2CoS

[15] Marchand, H. (1969). The categories and types of present-day English word formation. A Synchronic-diachronic approach. Munich: Beck

[16] Naaser, M.S.A. (2020). A computational morphological model for Arabic diminutive generation. International Journal of Linguistics and Translation Studies, 1(2), 19-34. http://doi.org/10.36892/ijlts.v1i2.45

[17] Nordquist, R. (2020, August 28). Diglossia in sociolinguistics. Retrieved $14^{\text {th }}$ January 2021, from https://www.thoughtco.com/diglossia-language-varieties-1690392

[18] Sadiq, S. (2016). Dialect convergence in Egypt: The impact of Cairo Arabic on Minya Arabic. [Unpublished Ph.D. thesi]. University of York, York, UK

[19] Saleh, M. (2017). Lexical variation in news headlines: A comparative study of Egyptian, Lebanese and Moroccan written Arabic. [Unpublished MA thesis]. American University in Cairo. Retrieved $14^{\text {th }}$ January 2021, from https://fount.aucegypt.edu/etds/1331 
[20] Stamp, R., Schembri, A., Fenlon, J., Rentelis, R., Woll, B., \& Cormier, K. (2014). Lexical variation and change in British sign language. PLOS ONE, 9(4), 1-14. https://doi.org/10.1371/journal.pone.0094053.g001

[21] Wardhaugh, R. \& Fuller, J.M. (2006). An introduction to linguistics. Oxford: Blackwell Yule, G. (2003). The Study of Language. Cambridge: Cambridge University Press. 